\title{
Take-up of Free School Meals: Price Effects and Peer Effects
}

\author{
Angus Holford*
}

September 22, 2014

\begin{abstract}
$29 \%$ of the 1.4 million eligible children do not participate in the UK's Free School Meals programme. Like other welfare benefits, take-up of Free School Meals is deterred by stigma and lack of information. This paper uses a fixed-effect instrumental variables strategy to evaluate the role of peer-group participation in overcoming these barriers. Identification of endogenous peer effects is achieved by exploiting a scheme which extended Free School Meal entitlement to all children in some areas. Results show that a 10 percentage point rise in peer-group take-up reduces non-participation by $3.3-4.0$ percentage points, or between $29 \%$ and $35 \%$.
\end{abstract}

Keywords: Free school meals, peer effects, welfare stigma, instrumental variables

JEL classifications: H75, I28, I38

${ }^{*}$ Institute for Social and Economic Research, University of Essex, Wivenhoe Park, Colchester, CO4 3SQ, UK. E-mail: ajholf@essex.ac.uk. Tel: +44 (0)1206 874280 


\section{INTRODUCTION}

In the UK, over 1.4 million children from low income households or without a parent in full time employment are entitled to receive a Free School Meal (FSM) at lunchtime each schoolday. This in-kind benefit is worth $£ 437$ per child per year to eligible households, whose incomes are less than $£ 16,190$ per year. FSMs represent a social safety net against malnutrition, which hinders physical and cognitive development and increases the likelihood of disruptive classroom behaviours (Lambert et al, 2004; Sorhaindo and Feinstein, 2006). This objective is undermined by nonparticipation. $14 \%$ of those entitled to FSMs are not registered to receive them (Iniesta-Martinez and Evans, 2012), and 18\% of those registered fail to take it up (Department for Education, 2012). This paper uses a fixed-effect instrumental variables strategy to identify endogenous peer effects in take-up of FSMs, conditional on registration. We exploit policy induced variation in the cost of school meals to pupils not registered for FSMs. These changes had no direct effect on FSMregistered pupils, for whom meals were always free. Results show that a 10 percentage point rise in peer-group take-up of school meals increases take-up among FSM-registered individuals by 3.3 4.0 percentage points. This is equivalent to reducing non-participation by between $29 \%$ and $35 \%$.

The first stage in identifying peer effects is to tackle the two-way causation of individual and peer-group behaviour (the 'reflection problem': Manski, 1993, Moffitt, 2001), and to distinguish 'endogenous peer effects' (individual behaviour being affected by peer-group behaviour) from 'contextual peer effects' (individual behaviour being affected by peer-group characteristics). This requires an exogenous source of variation in peer-group participation that has no direct effect on an individual's own take-up (Cohen-Cole and Zanella, 2008). This paper follows Dahl et al. (2012) in exploiting a reform which directly reduced the cost of participation for some individuals but not for others.

The second stage is to distinguish between mechanisms. Welfare participation can be deterred by stigma - the disutility or psychic cost associated with receipt of a welfare entitlement (Moffitt, 1983) - and lack of information about the programme and its benefits. These deterrents directly affect the level of take-up but the literature on peer effects in welfare participation evaluates how the strength of these deterrents is reduced by increasing take-up among an individual's social network (Aizer and Currie, 2004; Cohen-Cole and Zanella, 2008; Dahl et al, 2012). This is done with detailed reference to institutional arrangements and individual characteristics. For example, James (2012) addresses registration for FSMs. Entitlement to FSMs is widely used as a proxy indicator for poverty or low income status (Hobbs and Vignoles, 2007). This stigmatising label will 
deter registration if parents anticipate their child's status becoming observable to others. James (2012) argues that anonymised payment for school meals will eliminate this stigma, but not hinder information sharing within peer groups. Following Aizer and Currie (2004), James (2012) also assumes that information sharing will not affect the participation of individuals who have claimed previously. With these arguments, James (2012) shows information sharing to be the dominant channel for peer effects in deprived areas with high entitlement to FSMs, and alleviation of stigma most important in areas with few children entitled to FSMs. In contrast, by showing that the effect of introducing universal entitlement to FSMs was the same in schools with anonymised payment (where stigma could exist) and without (where it will not), our results do not support any role for this form of stigma in deterring take-up of FSMs conditional on registration (see Table 1 in section II.4).

All these papers also recognize that the magnitude of peer effects will depend on the strength and frequency of interactions between an individual and different groups of peers. In particular, Dahl et al. (2012) show significant positive peer effects on paternity leave take-up among the coworkers of fathers benefiting from a reform, but not on female coworkers' husbands, with whom opportunities for information sharing will be less frequent. In the FSM context, we expect the strongest peer effects within school classes.

Despite a substantial body of qualitative research exploring the reasons for non-participation in FSMs (Storey and Chamberlin, 2001; Harper and Wood, 2009; Nelson et al., 2012), this paper is the first to identify and quantify endogenous peer effects in take-up for registered students. We focus on primary schools, for children aged 4-11. Here, all children, whether FSM-registered or unregistered, can choose whether to take a school meal, or bring a packed lunch from home. Those taking a school lunch choose from the same menu and eat at the same tables in the same space, regardless of FSM-registration status. All FSM-unregistered pupils are charged the same price. To limit queueing pupils are usually brought in to eat class-by-class. Those bringing a packed lunch may eat either at the same tables as those taking a school meal ( $56 \%$ of schools), at separate tables in the same room (33\%), or in a separate room (11\%) (School Food Plan, 2013; Children's Food Trust, 2012). In this empirical setting, the stigma mechanism for peer effects is driven by the practice of separating those eating school meals from those bringing packed lunches. This means that to take up their entitlement, FSM-registered pupils need to sit apart from their packed-lunch eating friends. The greater the peer-group take-up of school meals, the smaller the expected disutility this will create. The information mechanism operates by peer-group take-up acting as a signal for quality of school meals. Increasing peer-group take-up will induce some children to try 
school meals either for the first time or to revise their existing beliefs. ${ }^{1}$ We expect this mechanism to be strongest with respect to FSM-unregistered peers, who signal a positive willingness to pay. We condition on registration for FSMs. This means there is no role for information transmission about eligibility or the application process.

\section{INSTITUTIONAL BACKGROUND}

\section{II.1 Means-tested entitlement}

FSMs are a means-tested benefit. Children are entitled to FSMs if a parent receives a 'qualifying benefit' for being out-of-work, in-work but earning a sufficiently low household income (less than $£ 16,190$ per year, regardless of family size), a state pensioner, or an asylum seeker. ${ }^{2}$ Parents then need to register their child to receive FSMs by completing a short form and providing proof of entitlement to their Local Education Authority (LEA). This does not happen automatically, and there is no system to alert parents when they become eligible. At the start of each subsequent academic year, parents of FSM-registered children are asked to re-register, declaring they are still entitled.

\section{II.2 Pilot scheme of 'universal entitlement'}

A pilot scheme for 'universal' entitlement to FSMs took place in Scotland during the 2007-08 academic year. It was implemented in five LEAs, containing $25 \%$ of the population. The intervention meant that free school lunches were made available to all children in the first three years of primary school (years P1-P3, containing children aged 4-7 at the start of the school year), regardless of their FSM-registration status. The pilot was designed to assess the practical difficulties and costs that would be associated with implementing universal entitlement permanently, either throughout Scotland or in a subset of schools with the most deprived intake of pupils. The pilot-area LEAs were therefore chosen to include areas of high deprivation, but to be geographically dispersed and contain a variety of large urban areas, small towns, and rural areas (MacLardie et al, 2008, p.3). The scheme was not designed to coincide with any change in the nutritional content or quality of school meals (MacLardie et al, 2008, p.47), and there was no associated campaign to raise take-up among children already registered for FSMs.

In Scotland, the school year runs from mid-August to the end of June. Our data come from the School Meal Census, taken in February each year. The scheme was announced on 11th July 2007 to 
run from 22nd October 2007 to 31st March 2008. This means there will be no anticipation effects on registration or take-up entering our 2007 data. Moreover, parents asked to renew registration in August 2007, or becoming eligible to register their child for FSMs after this date, still needed to register in order to claim FSMs during the rest of the 2007-2008 school year. The scheme was later extended to June 2008, but this announcement took place on 25th March 2008, which is after the February School Meal Census. ${ }^{3}$ This means we can treat registration for FSMs as exogenous with respect to the pilot scheme.

From August 2008, the arrangements for FSM provision fully reverted to the pre-pilot situation. Our estimation sample ends in February 2010. Some LEAs introduced limited extensions to entitlement for one year from August 2010 but we expect no anticipation effects on take-up or registration behaviour in the previous school year.

\section{II.3 Trends in take-up of school meals}

Figures 1 and 2 plot the take-up rate of school meals in February each year for FSM-unregistered and registered pupils respectively. It is clear that schools exposed to the pilot scheme in 2008 experienced a substantial rise in take-up among both groups, but the variation over time for all areas shows there are other factors at work. Figure 1 shows a negative trend in take-up of paid-for school meals in the pilot areas relative to the rest of Scotland both before and after the pilot scheme. This is likely to be because pilot areas have a greater prevalence of households which are poor yet ineligible for FSMs. These households would be more sensitive to price rises, and more vulnerable to income shocks caused by the post-2007 recession, that would make school meals less affordable. Figure 2 shows that the take-up rate among FSM-registered pupils declined over the four years before the pilot scheme, in both pilot and non-pilot areas. Although the overall decline was steeper in pilot areas, both saw the steepest decline from 2004-2005, fairly static take-up from 2005-2006, and a slower decline from 2006-2007. This suggests that all LEAs are subject to the same time-varying shocks, but these shocks have a larger effect on more deprived school intakes. If endogenous peer effects exist, the relative decline in unregistered take-up in pilot areas (as seen in figure 1) will contribute to this effect. Note the continued decline in non-pilot area FSM-registered take-up into 2008. Given the common trends observed elsewhere, this provides evidence against the rise in pilot area take-up in that year being due to mean-reversion or a different random shock not related to the pilot scheme.

[Figures 1 and 2 about here] 


\section{II.4 Effects of the pilot scheme}

The pilot scheme directly targeted FSM-unregistered individuals, who usually were required to pay. Figure 1 shows that in 2008, the year of the intervention, take-up in pilot areas rose by 15 percentage points. Assuming no defiers, this means that $23 \%$ of those previously taking a packed lunch were persuaded to take a school lunch instead. For the registered group (who never had to pay), Figure 2 shows that take-up rose by 5 percentage points from 2007 to 2008. Assuming no defiers, this means that $34 \%$ of FSM registered students previously foregoing their entitlement were persuaded to start taking it. In this regard, universal entitlement was more persuasive for the FSM-registered group, for which it provided no financial incentive to change arrangements.

A possible explanation is that extending FSMs to all students meant FSM-registered children were no longer identifable when claiming their school meal. This would eliminate any resulting stigma. If this were true, we would expect a smaller effect of universal entitlement in schools which already ensured FSM-registered pupils could claim their school meal anonymously. However, Table 1 shows that the reduced form effect of universal entitlement on take-up by FSM-registered pupils was the same in these schools as those without anonymised payment (compare the coefficients in columns 3 and 4). ${ }^{4}$ This paper instead shows that peer-effects are responsible: FSM-registered individuals became more likely to participate because more of their peers did so.

[Table 1 about here]

\section{EMPIRICAL MODEL AND IDENTIFICATION STRATEGY}

This section models take-up of FSMs using the linear-in-means framework proposed by Manski (1993). This method is standard in applications of peer effects for its tractable functional form and absence of parametric assumptions. We first set out a model of individual behaviour with distinct effects of peer-group take-up by FSM-unregistered classmates (who signal their willingness to pay) and FSM-registered classmates (who do not). However, our data are not available at the individual level. We therefore show that the parameters of this model are retained when variables are aggregated across FSM-registered individuals within each school, but that the peer effects of interest are not identified without further restrictions. We demonstrate that identification is achieved by assuming that individuals respond equally to the take-up behaviour of registered and unregistered classmates. In our empirical application we ensure this assumption will hold by restricting estimation to schools with anonymised payment. 


\section{III.1 Model of individual behaviour}

Consider the following demand equation for individual $i$, who is registered for FSMs (hence the superscript ' $f$ '), in school $j$ at time $t$. Here, $y_{i j t}^{f}$ equals 1 if individual $i$ takes a free school lunch, and zero otherwise. The variable $\rho_{[-i] j t}^{f}$ represents the proportion of the remaining pupils in the school who are also registered for FSMs, and $\bar{y}_{[-i] j t}^{f}$ and $\bar{y}_{j t}^{n}$ the take-up rate of school meals among (i) other FSM-registered pupils and (ii) the population of FSM-unregistered pupils, respectively. A vector of individual controls affecting participation $\left(\mathbf{X}_{i j t}^{f}\right)$, and school level characteristics $\left(\mathbf{Z}_{j t}\right)$ are controlled for, along with a school fixed effect $\left(\eta_{j}\right)$ and year effect $\left(e_{t}\right)$. Finally, $\epsilon_{i j t}$ is an individual error term.

$$
\begin{array}{r}
y_{i j t}^{f}=\alpha+\psi \rho_{[-i] j t}^{f}+\gamma \rho_{[-i] j t}^{f} \bar{y}_{[-i] j t}^{f}+\delta\left(1-\rho_{[-i] j t}^{f}\right) \bar{y}_{j t}^{n} \\
+\phi \mathbf{X}_{i j t}^{f}+\theta \mathbf{Z}_{j t}+\eta_{j}+e_{t}+\epsilon_{i j t}
\end{array}
$$

In this structure, the coefficient $\psi$ captures the effect of changing eligibility for FSMs among individual $i$ 's classmates. This is a contextual peer effect. The coefficients $\gamma$ and $\delta$ capture the effect of changing take-up of school meals among FSM-registered and unregistered peers. The magnitude of these endogenous peer effects also depends on the relative prevalence of each type of schoolmate $\left(\rho_{[-i] j t}^{f}\right.$ and $\left.\left(1-\rho_{[-i] j t}^{f}\right)\right)$.

\section{III.2 Model with aggregated data}

Aggregating and averaging equation (1) across FSM-registered individuals in school $j$ yields equation (2). This is written in terms of variables which can be derived from the school-level dataset, but the coefficients on their individual-level counterparts from equation (1) are retained.

$$
\begin{array}{r}
\bar{y}_{j t}^{f}=\alpha+\psi \rho_{[-i] j t}^{f}+\gamma \rho_{[-i] j t}^{f} \bar{y}_{j t}^{f}+\delta\left(1-\rho_{[-i] j t}^{f}\right) \bar{y}_{j t}^{n} \\
+\phi \overline{\mathbf{X}}_{j t}^{f}+\theta \mathbf{Z}_{j t}+\eta_{j}+e_{t}+\bar{\epsilon}_{j t}
\end{array}
$$

The dependent variable is now $\bar{y}_{j t}^{f}$, the proportion of FSM-registered individuals who take a school meal. The variables $\rho_{[-i] j t}^{f}, \bar{y}_{j t}^{n}, \mathbf{Z}_{j t}$ and $\eta_{j}$ are constant across FSM-registered individuals within the school at time $t$, and so impervious to aggregation. Individual characteristics $\mathbf{X}_{i j t}^{f}$ aggregate to the school-level mean $\overline{\mathbf{X}}_{j t}^{f}$, so can no longer be identified separately from the contextual effects of $\mathbf{Z}_{j t}$. In addition, the FSM-registered peer-group take-up rate $\left(\bar{y}_{[-i] j t}^{f}\right)$ aggregates to $\bar{y}_{j t}^{f}$. This 
is equal to the dependent variable. As $\rho_{[-i] j t}^{f}$ has its own direct effect on FSM-registered takeup, there is no exogenous source of variation in the construct $\left(\rho_{[-i] j t}^{f} \bar{y}_{j t}^{f}\right)$ which can break this functional dependence. The parameter $\gamma$ is therefore not identified.

However, with an additional restriction it is feasible to identify endogenous peer effects based on variation in take-up by the unregistered group only. One approach would be to regress FSMregistered take-up on FSM-unregistered take-up $\left(\bar{y}_{j t}^{n}\right)$ only. The coefficient on $\bar{y}_{j t}^{n}$ in the corresponding reduced form equation is equal to $\left[\delta\left(1-\rho_{[-i] j t}^{f}\right)\right] /\left[1-\gamma \rho_{[-i] j t}^{f}\right]$. This is the 'social multiplier', or overall effect of a change in FSM-unregistered take-up on FSM-registered take-up. The true social multiplier should vary across schools according to $\rho_{[-i] j t}^{f}$, but the coefficient obtained by estimating this regression will tell us only the mean social multiplier across all schols. Moreover, the two parameters $\delta$ and $\gamma$ will not be identified from this single estimated coefficient. Instead, we impose the restriction $\gamma=\delta$. This means we assume that if endogenous peer effects exist, then participation decisions condition on the proportion of all other pupils who take a school meal, rather than distinguishing between the FSM registered and unregistered groups. This proportion, labelled $\bar{Y}_{[-i] j t}$, is equal to the following weighted average:

$$
\bar{Y}_{[-i] j t}=\left(\rho_{[-i] j t}^{f} \bar{y}_{j t}^{f}\right)+\left(1-\rho_{[-i] j t}^{f}\right) \bar{y}_{j t}^{n}
$$

The restricted version of equation (2) is then written:

$$
\bar{y}_{j t}^{f}=\alpha+\psi \rho_{[-i] j t}^{f}+\gamma \bar{Y}_{[-i] j t}+\phi \overline{\mathbf{X}}_{j t}^{f}+\theta \mathbf{Z}_{j t}+\eta_{j}+e_{t}+\epsilon_{i j t}
$$

We support this identifying assumption by limiting estimation to schools with anonymised payment. This can be implemented with an electronic 'swipe card' system, but cruder methods such as requiring 'payment' at the start of the week in an envelope, which can be left empty if required, are also used. From the perspective of a child, this removes any visible difference between his FSM-registered and unregistered peers when taking school lunch, and makes the distinction between these groups irrelevant.

The functional dependence of the explanatory variable $\left(\bar{Y}_{[-i] j t}\right)$ on the dependent variable $\left(\bar{y}_{j t}^{f}\right)$ is addressed through a fixed-effect instrumental variable strategy exploiting two exogenous sources of variation in FSM-unregistered take-up $\left(\bar{y}_{j t}^{n}\right)$. Firstly, the implementation of the universal entitlement pilot scheme, which raised take-up among FSM-unregistered children by reducing the price of school meals to zero, but did not target the FSM-registered group in any way. Secondly, the price charged for school meals, which are determined by LEAs in negotiation with their catering contractor. These rose by an average of $£ 0.05$ each year, including some extended price 
freezes but also a variety of rises and reductions of up to $£ 0.75$ at one time. ${ }^{5}$ Higher prices will reduce demand among the unregistered group, but the unobserved factors determining the level and timing of price changes should be uncorrelated with the decisions of FSM-registered pupils, for whom the price is always zero. Conditional on school fixed effects and time-varying observable characteristics therefore, neither of these instruments should have a direct effect on take-up by the FSM-registered group.

Letting $p_{j t}$ represent the price-when-charged for a school meal in school $j$ at time $t, u_{j t}$ be a dummy equal to 1 for schools exposed to universal FSM-entitlement at time $t$, and $\chi_{j t}$ all the remaining explanatory variables, our instrumental variables specification (counterpart to the 'OLS' specification of equation 4) can be defined as follows:

$$
\begin{array}{r}
E\left[\bar{y}_{j t}^{f} \mid p_{j t}, u_{j t}, \boldsymbol{\chi}_{j t}\right]=\alpha+\psi \rho_{[-i] j t}^{f}+ \\
+E\left[\bar{Y}_{[-i] j t} \mid p_{j t}, u_{j t}, \boldsymbol{\chi}_{j t}\right] \\
+\phi \overline{\mathbf{X}}_{j t}^{f}+\theta \mathbf{Z}_{j t}+\eta_{j}+e_{t}
\end{array}
$$

Here, $E\left[\bar{Y}_{[-i] j t} \mid p_{j t}, u_{j t}, \boldsymbol{\chi}_{j t}\right]$ is the fitted value of peer-group take-up from the first-stage regression. The parameter $\gamma$ (estimates of which are presented in Table 5) represents the first-round effect of an exogenous change in peer group participation $\bar{Y}_{[-i] j t}$ on take-up by the FSM-registered group. In the presence of endogenous peer effects this initial change will have second and subsequent round feedback effects. These will vary according to the social multiplier, which is evaluated in sections IV.4 and IV.5, below.

\section{III.3 Data and estimation}

This paper uses a dataset on every primary school (for children aged 4-11) in Scotland from 2003-2013. This was created by merging data files published on the Scottish Government and Scottish Index of Multiple Deprivation websites. ${ }^{6}$ The School Meal Census documents for each school the number of children (i) enrolled, (ii) present at school, and (iii) taking a school meal, both in total and separately by FSM-registration status. From these data we derive values for $\bar{y}_{j t}^{f}, \bar{Y}_{[-i] j t}$ and $\rho_{[-i] j t}^{f}$, as used in equation (5). These are measured on a specific "representative" survey day in February each year, and aggregate children in all seven years of primary school. The data are not separated by year-group or school class. The Census also indicates whether the school has a system to anonymise payment for school meals. The prices charged by each LEA for a standard school meal are published separately. The SIMD provides contextual data on the immediate surrounding area. 
A limitation to these data is that variables designed to capture 'contextual' school-level effects will be correlated with the means of unobserved individual characteristics. For example, $\rho_{[-i] j t}^{f}$ is equal to the proportion of an FSM-registered pupils' schoolmates who are also registered for FSMs. This is included to capture a contextual peer effect on take-up, but registration for FSMs is also the only available school-level proxy for students' socio-economic status. Although we include the SIMD deprivation ranking to proxy for these same unobserved characteristics, this means we cannot expect the coefficient on 'peer-group registration' $\left(\rho_{[-i] j t}^{f}\right)$ to be interpretable as a contextual peer effect.

With these data, peer-groups are defined at the school level. Friendship groups and signalling will occur predominantly within school classes and cohorts, but capacity constraints, sibling correlations, and mixing of cohorts in smaller schools will all generate cross-cohort spillovers. This means that although whole-school peer-groups represent a larger social network than relevant for the mechanisms of interest, we do encompass all the peer and spillover effects in operation.

Unless otherwise stated, all estimates presented in this paper are school and year fixed-effect regressions. Because universal entitlement and price both vary only across LEAs, not individual schools, all standard errors and diagnostic tests adjust for 32 LEA clusters. Because the data comprise within-school means but are generated by individual-level behaviour, we weight observations in proportion to the number of students present and registered for FSMs on the survey day. ${ }^{7}$

\section{RESULTS}

\section{IV.1 Selection into anonymised payment}

Identification of the endogenous peer effect parameter $\gamma$ in equation (5) relies on the assumption that FSM-registered individuals respond equally to take-up by their FSM-registered and unregistered peers. We support this assumption by restricting estimation to schools with anonymised payment.

Table 2 shows how coverage of anonymised payment expanded from 497 schools (22\%) in 2004 to $1,618(76 \%)$ in 2010 . Table 3 shows that schools with universal entitlement were less likely to use anonymised payment. Though not statistically significant this is expected, because universal entitlement reduces the number of FSM-registered children perceived to benefit from it. Schools with anonymised payment also tended to be situated in less deprived areas, though this difference 
in ranking reflects only a small absolute difference in deprivation.

The left-hand panel of Table 3 shows that in 2008 schools with anonymised payment were very similar to those without in terms of the price charged, take-up rate of school meals, overall school size and registration for FSMs. The right hand panel of Table 3 presents random effects linear probability model coefficients showing that none of these school characteristics had a statistically significant or economically large effect on use of anonymised payment in the following year. For these reasons we argue that the results obtained by restricting estimation to schools with anonymised payment would generalize to the remaining schools in Scotland, were they to introduce such systems.

[Tables 2 and 3 about here]

\section{IV.2 Reduced form results}

Table 4 presents reduced form regressions for take-up of school meals. These are presented separately for FSM-registered and non-registered pupils, and for both the whole of Scotland (columns 1-2) and non-pilot areas never exposed to universal entitlement (columns 3-4). Column 2 represents the reduced form of both the first ('All') and second ('Price in 2nd stage') instrumental variable specifications discussed in section IV.3 (see Table 5), and column 4 the reduced form of the third ('Non-pilot only') specification.

[Table 4 about here]

Table 4 shows a positive and significant effect of universal FSM entitlement, and a negative and significant effect of the price on take-up by FSM-registered students (columns 2 and 4). This is in line with the direct effects of these instruments on take-up by their FSM-unregistered peers and the expected positive peer effect. Universal entitlement raised take-up among FSM-unregistered pupils by approximately 14 percentage points (column 1), and imputing a price of $£ 1.50$ and paid-for take-up of $38 \%$, the coefficients on price for FSM-unregistered students correspond to a price elasticity of demand of approximately - 0.43 (columns 1 and 3). Both effects are economically large and statistically significant.

It is plausible that the negative reduced form coefficient on price for FSM-registered pupils is attenuated by a positive direct effect of the price signal. This may occur if parents of FSM-registered pupils perceive increases in price as a proxy for improvements in quality. We demonstrate in the 
next section that our results are robust to including price in the second-stage equation for FSMregistered take-up. The 'direct effect' of price is shown to be negative, small and insignificant. Raising the peer-group registration rate significantly reduces FSM-registered take-up. This reflects persistence in individuals' preferences, which means that newly eligible pupils (responsible for the increase in FSM-registration) will be more likely to take a packed lunch than existing registered pupils. The same argument in reverse delivers the positive (though insignificant) sign for the FSMunregistered group. Increasing the school intake has essentially zero effect on FSM-registered takeup, but the capacity constraints associated with a growing intake do deter participation by FSMunregistered pupils. The effect is small but precisely estimated: an extra 18 students, adding $10 \%$ to the mean school size, would reduce take-up by 0.7 percentage points. The interaction between total school intake and peer-group registration rate is included because we expect important unobserved differences in the school composition to be correlated with changes in school size. Immigrant and ethnic-minority students are likely to be concentrated in large inner-city schools, for example. We have no prior about the sign on these coefficients, though this variable adds precision to estimates in all our specifications. Finally, reducing the area's relative deprivation has essentially zero effect on take-up by either group (though the coefficient is negative in all four regressions).

\section{IV.3 Structural estimates}

Estimates for three versions of the final model of demand for FSMs (equation 5) are presented in Table 5. In each case, we present the first-stage regression for peer-group take-up $\left(\bar{Y}_{[-i] j t}\right)$, the OLS regression coefficients for FSM-registered take-up $\left(\bar{y}_{j t}^{f}\right)$, and the second stage instrumental variables results for FSM-registered take-up. The parameter of interest is $\gamma$, the coefficient on peer-group take-up $\left(\bar{Y}_{[-i] j t}\right)$. This represents the mean first-round effect of a 1 percentage point rise in peer-group take-up of school meals on the take-up rate by FSM-registered individuals. The final magnitude of endogenous peer effects depends on the social multiplier, which is evaluated in the next section (IV.4).

[Table 5 about here]

The first specification ('All') is based on schools with anonymised payment in every LEA in Scotland. Both universal FSM entitlement and the price are excluded from the second-stage. These variables are jointly significant in the first stage and the F-statistic of 33.024 is large in absolute value. The Hansen J-statistic indicates we cannot reject the null hypothesis that the 
overidentifying restrictions are valid. The estimate of $\gamma$ of 0.382 is statistically significant at the $1 \%$ level. This can be interpreted as the mean effect of an exogenous change in overall peergroup take-up $\left(\bar{Y}_{[-i] j t}\right)$ caused by either price variation or universal entitlement, on take-up by FSM-registered individuals across all seven year groups.

The second specification ('Price in 2nd stage') uses the same estimation sample, but permits the price to have a direct effect on FSM-registered take-up in the second stage. The F-statistic for universal entitlement of 29.256 is almost as large as in the first specification ('All'). This demonstrates that the price contributes relatively little identifying variation. The estimate of $\gamma$ of 0.329 can be interpreted as the lower bound of the effect of an exogenous change in peer-group take-up caused by the pilot reform on take-up by FSM-registered individuals in the targeted yeargroups. In making welfare comparisons between policy interventions in section IV.5, the upper bound will be evaluated. The coefficient on price in the equation for FSM-registered take-up is negative, small, and statistically insignificant at all conventional levels. This should mitigate concerns that increases in price, if interpreted as a proxy for changes in quality, may have a positive direct effect on FSM-registered take-up.

The final specification ('Non-pilot only') limits the estimation sample to schools in non-pilot LEAs, which were never exposed to universal FSM entitlement. The F-statistic of 10.182, although statistically significant at the $1 \%$ level, is small in absolute value. This confirms the weak identifying power of price alone. The estimate of $\gamma$ of 0.400 is similar in magnitude to those endogenous peer effects estimated using the pilot reform, but somewhat less precisely estimated.

In each specification the 'OLS' coefficient on peer-group take-up is smaller, though not statistically different from the second stage instrumental variable coefficient. This suggests there are unobserved factors which raise FSM-unregistered take-up but reduce FSM-registered take-up. For example, affluent parents of FSM-unregistered pupils may respond positively to a 'healthier' menu on a specific day of the week coinciding with the School Meal Census, while some FSM-registered children may resist this change, leading to lower FSM-registered take-up on these days. These factors must dominate the effects of reverse causality (FSM-unregistered take-up being positively affected by FSM-registered take-up) or the positive functional dependence of $\bar{Y}_{[-i] j t}$ on $\bar{y}_{j t}^{f}$.

\section{IV.4 The social multiplier}

Knowing the decomposition of $\bar{Y}_{[-i] j t}$ into $\bar{y}_{j t}^{f}$ and $\bar{y}_{j t}^{n}$ according to equation (3), the final empirical specification (equation 5) can be rearranged into a reduced form to obtain the 'social multiplier', 
or overall effect of a change in FSM-unregistered participation on FSM-registered participation: ${ }^{8}$

$$
\frac{\partial E\left[\bar{y}_{j t}^{f} \mid p_{j t}, u_{j t}, \boldsymbol{\chi}_{j t}\right]}{\partial E\left[\bar{y}_{j t}^{n} \mid p_{j t}, u_{j t}, \boldsymbol{\chi}_{j t}\right]}=\frac{\gamma\left(1-\rho_{[-i] j t}^{f}\right)}{1-\gamma \rho_{[-i] j t}^{f}} .
$$

We have the data to evaluate two potential interventions to achieve this initial rise in participation. The first is to target universal entitlement at the youngest three year-groups within schools. The second is to reduce the price which all unregistered pupils are charged. Substituting the estimates of $\gamma=0.329$ from the 'Price in 2nd stage' specification in Table 5, and $\gamma=0.400$ from the 'Non-pilot only' specification, the social multipliers for these interventions vary according to the proportion of an FSM-registered pupil's peers who are also FSM-registered $\left(\rho_{[-i] j t}^{f}\right)$ as shown in Table 6. Intuitively, a given rise in FSM-unregistered take-up corresponds to a larger change in overall peer-group take-up and produces a larger social multiplier, the smaller is $\rho_{[-i] j t}^{f}$. This dominates the greater potential for second round feedback effects in schools where FSM-registered individuals are more prevalent.

[Table 6 about here]

\section{IV.5 Evaluating policy interventions}

Multiplying the social multipliers in the first line of Table 6 by 14.4 percentage points; the reduced form coefficient on universal entitlement for FSM-unregistered take-up in column 1 of Table 4; we can infer that introducing universal entitlement to the youngest three year-groups would reduce non-participation among FSM-registered pupils across the whole school by between 3.3 and 4.6 percentage points, or by between $28 \%$ and $40 \%$ from the 2013 level. With reference to the social multipliers in the second line of Table 6 and reduced form coefficients on price in columns 1 and 3 of Table 4, we can infer that to achieve this same reduction in non-participation, it would be necessary to reduce the price charged to all unregistered pupils by $£ 1.10$.

The universal entitlement option is fiscally superior, entailing a smaller reduction in revenue for the same rise in costs. Furthermore, these figures represent only the lower bound for the effect on takeup in the year-groups affected by the reform. The upper bound can be defined by assuming (i) that universal entitlement has no effect on FSM-unregistered take-up outside the targeted year-groups, and (ii) that there are no cross-year-group peer effects. If FSM-registered and unregistered pupils are distributed evenly across the seven year-groups within each school, the effect of introducing universal entitlement is then to raise FSM-unregistered take-up in the three affected year-groups 
by 33.6 percentage points $((7 / 3) \times 14.4$ percentage points $)$. This will reduce FSM-registered nonparticipation by between 7.7 and 10.7 percentage points or by between $67 \%$ and $93 \%$ from the 2013 level.

Evidence from the official pilot-scheme evaluation suggest that the true effect will be close to this upper bound. MacLardie et al. (2008) use data from a pre-trial survey in October 2007 with data collected with the School Meal Census in February 2008. These data do separate individuals in school years P1-P3 (targeted) from P4-P7 (not targeted), but are not publicly available. FSM-unregistered take-up in pilot area schools rose by 27.6 percentage points for school years P1-P3, and 2.9 percentage points for school years P4-P7. This suggests a very small direct effect of universal entitlement outside the affected year-groups. FSM-registered take-up rose by 4.4 percentage points in year-groups P1-P3 and 1.4 percentage points in year-groups P4-P7. This supports our expectation that peer effects are stronger within year-groups, but show that an assumption of no cross-year peer-effects is clearly false (MacLardie et al., 2008, table 3.7).

Dynamic considerations raise an additional argument in favour of targeting the youngest yeargroups, rather than a general price reduction. Making school lunch participation a social and household norm is likely to be easier before individuals have established their own routines. Early exposure to universal entitlement should then generate persistently higher take-up of both paid-for and free school meals among these cohorts in subsequent years. Figures (1) and (2) bear out an ongoing positive effect of temporary exposure to the pilot scheme for both these groups, at least relative to previous trends. We would expect this lagged effect to be larger for a permanent reform providing a longer exposure to the treatment.

\section{DISCUSSION AND CONCLUSIONS}

This paper has identified significant positive endogenous peer effects in take-up of Free School Meals (FSMs), a means-tested welfare benefit available to 1.4 million UK children from low income households. Using a fixed effect instrumental variables strategy exploiting policy induced variation in the cost of school meals to pupils not eligible for FSMs, it is shown that a 10 percentage point rise in peer-group participation induces a $3.3-4.0$ percentage point rise in participation among FSM-registered pupils. This is equivalent to reducing non-participation by between $29 \%$ and $35 \%$. This endogenous peer effect is derived from a combination of two mechanisms. Firstly the practice of separating those eating school meals from those bringing packed lunches creates a disutility of participation which is mitigated by higher peer-group take-up. Consistent with the wider literature 
on peer effects in welfare participation, we refer to this mechanism as 'stigma'. 9

Secondly increasing peer-group participation signals that school lunches are an increasingly attractive offer. This will persuade some FSM-registered individuals to try FSMs either for the first time or to revise their existing perceptions. This information mechanism stems from FSMs being both a welfare entitlement and a consumer good of uncertain quality. This has implications for harnessing peer-group participation to raise take-up of other programmes by those most in-need or otherwise hardest to reach. For example, in the UK an entitlement to 15 hours per week of 'early education' for disadvantaged two year-olds was extended to $40 \%$ of the cohort from September 2014. Increasing take-up among this marginal group should help persuade the most disadvantaged parents of the programme's benefit.

To identify the relative importance of these two mechanisms would require retrospective data documenting the timing and seating arrangements implemented at lunchtime in each school. This would be a prohibitive task, and the resulting data fraught with non-response and recall error. We expect the information mechanism to apply in every school, but know that this form of stigma will apply only in schools enforcing separate tables or spaces for those eating packed lunches. This covers $44 \%$ of schools, according to the evidence base for the UK government's current 'School Food Plan'. Nevertheless, by showing that the pilot scheme of universal entitlement had the same effect on take-up by FSM-registered children in schools with and without anonymised payment, we infer that the potential stigma from being identifiable as FSM-registered does not significantly deter take-up among registered children.

Universal entitlement to Free School Meals for children in the first three years of school have been implemented at every state-funded primary school in England from September 2014 and Scotland from January 2015. ${ }^{10}$ These reforms will cost $£ 650 \mathrm{~m}$ per year, and directly target 1.665 million children. The scheme has been criticised as poorly targeted, with a high opportunity cost, since the majority of direct beneficiaries will come from higher socio-economic backgrounds (The Economist, Leader, September 21st 2013; Adams, The Guardian, September 18th 2013). The evidence presented here suggests that peer effects in take-up mean that the reform will substantially reduce non-participation in FSMs among those already registered, by at least $28 \%$ and up to $93 \%$ in the first year. For this reason, we expect universal FSM-entitlement to yield significant financial, health and educational benefits for children from the most deprived households. 


\section{ACKNOWLEDGEMENTS}

This work was carried out during PhD studies supported by an Economic and Social Research Council ' $1+3$ ' studentship in Economics [reference number ES/I025499/1], supervised by Emilia Del Bono and Stephen Pudney. Thanks to two anonymous referees for their helpful comments, as well as seminar participants at Essex, CASE at the LSE, and EALE conference in Turin, 2013. All errors are my own. 


\section{REFERENCES}

Adams, R., 18 September 2013. Free school meals policy gets lukewarm reception from educationalists. The Guardian. URL: http://www.theguardian.com/education/2013/sep/18/ free-school-meals-lukewarm-reception.

Aizer, A., Currie, J., 2004. Networks or neighborhoods? Correlations in the use of publicly-funded maternity care in California. Journal of Public Economics 88, 2573-2585.

Cohen-Cole, E., Zanella, G., March 2008. Welfare stigma or information sharing? Decomposing social interactions effects in social benefit use. Working Paper 531, Department of Economics, University of Siena.

Dahl, G., Løken, K., Mogstad, M., 2012. Peer effects in program participation. Discussion Paper 6681, IZA.

Department for Education, 2012. Statistical first release SFR10: Schools, pupils and their characteristics.

Feinstein, L., Sorhaindo, A., 2006. What is the relationship between child nutrition and school outcomes? Research Report 18, Centre for Research on the Wider Benefits of Learning.

Haroun, D., Harper, C., Pearce, J., Wood, L., Sharp, L., Poulter, J., Hall, L., Smyth, S., Huckle, C., Nelson, M., 2012. Primary school food survey, 2009 (revised 2012). Technical report, Children's Food Trust.

Harper, C., Wood, L., 2009. Please Sir? Can we have some more? - Lessons from Free School Meal initiatives. Technical report, School Food Trust.

Hobbs, G., Vignoles, A., May 2007. Is Free School Meal status a valid proxy for socio-economic status (in schools research)? Research report, Centre for the Economics of Education.

Iniesta-Martinez, S., Evans, H., November 2012. Pupils not claiming Free School Meals. Research Report 235, Department for Education.

James, J., 2012. Peer effects in Free School Meals: Information or stigma? Working Paper 11, EUI Max Weber Programme.

Lambert, J., Agostoni, C., Elmadfa, I., Hulshof, K., Krause, E., Livingstone, B., Socha, P., Pannemans, D., Samartin, S., 2004. Dietary intake and nutritional status of children and adolescents in Europe. British Journal of Nutrition 92 (S2), S147-S211. 
MacLardie, J., Martin, C., Murray, L., Sewel, K., 2008. Evaluation of the free school meals trial for P1 to P3 pupils. Technical report, Scottish Government Social Research.

Manski, C. F., 1993. Identification of endogenous social effects: The reflection problem. Review of Economic Studies 60, 531-542.

Moffitt, R., 2001. Policy interventions, low-level equilibria, and social interactions. In: Durlauf, S. N., Young, H. P. (Eds.), Social Dynamics. Brookings Institution, Ch. 3, pp. 45-82.

Moffitt, R. A., 1983. An economic model of welfare stigma. American Economic Review 73, 10231035 .

Moretti, E., 2011. Social learning and peer effects in consumption: Evidence from movie sales. Review of Economic Studies 78, 356-393.

Nelson, M., Nicholas, J., Riley, K., Wood, L., 2012. Seventh annual survey of take up of school lunches in England. Technical report, Children's Food Trust.

OCC Strategy Consultants, 2013. School Food Plan Evidence Base. URL: www . schoolfoodplan. com/wp-content/uploads/2013/10/School-Food-Plan-Evidence_Pack_July_2013_Final. pdf, slide 39 .

Schaffer, M., 2010. xtivreg2: Stata module to perform extended IV/2SLS, GMM and AC/HAC, LIML and k-class regression for panel data models.

StataCorp, 2013. Stata user's guide, release 13.

Storey, P., Chamberlin, R., 2001. Improving the take up of free school meals. Research Report 270, Thomas Coram Research Unit, Institute of Education.

The Economist, 21 September 2013. Hands off: Britain's new interventionism, 16. 


\section{NOTES}

${ }^{1}$ Moretti (2011) has demonstrated this mechanism in the case of cinema sales. Potential audiences are shown to update their expectations of movie quality, and hence likelihood of attendance, as a result of higher or lower than expected sales the previous week.

${ }^{2}$ The eligibility criteria are listed here: http://www.scotland.gov.uk/Topics/Education/Schools/HLivi/schoolmeals (accessed 14 Nov 2013). The rules differ very slightly in England, Wales and Northern Ireland, as shown here: https://www.gov.uk/apply-free-school-meals (accessed 2 Sept 2014).

${ }^{3}$ Sources: http://news.bbc.co.uk/1/hi/scotland/6291812.stm, http://news.bbc.co.uk/1/hi/scotland/glasgow_ and_west/7054334.stm, http://www.scotland.gov.uk/News/Releases/2008/03/25113859, all accessed 27 Sept 2013.

${ }^{4}$ Complete estimation output for Table 1 is shown and further differences in observed behaviour between schools with and without anonymised payment are discussed in appendix A.2. (See online material).

${ }^{5}$ The evolution of prices in each LEA is shown in figures 6 (for pilot areas), 3, 4 and 5 (for non-pilot areas, in alphabetical order), in appendix A.4. (See online material).

${ }^{6}$ Data sources: School Meal Census at http://www.scotland.gov.uk/Topics/Statistics/Browse/School-Education/ Datasets; school meal prices at http://www.scotland.gov.uk/Topics/Statistics/Browse/School-Education/PubSchooMeals; Scottish Index of Multiple Deprivation at http://www.scotland.gov.uk/Topics/Statistics/SIMD/DataAnalysis, all accessed 12 April 2013. Prices and records of anonymised payment available for 2004-2010 only. Disclosive data (involving fewer than five individuals) is suppressed.

${ }^{7}$ Specifically we use 'analytic weights' designed for regression on observed means (see Stata User's Guide, release 13, p.319) with the 'xtivreg2' command (Schaffer, 2010) in Stata.

${ }^{8}$ The complete derivation of this expression is presented in appendix A.3. (See online material).

${ }^{9}$ In a majority of schools, overall take-up of school lunches is at $50 \%$ or more. We recognize that the term 'stigma' is usually attached to the decisions faced by smaller, minority pools of individuals.

${ }^{10}$ Education is a 'devolved issue'. This means the equivalent money has been provided to the Welsh and Northern Irish governments, but at time of writing neither has announced whether or how they will implement this reform. 
Figure 1: Take-up rate of school lunches: Pupils not registered for Free School Meals

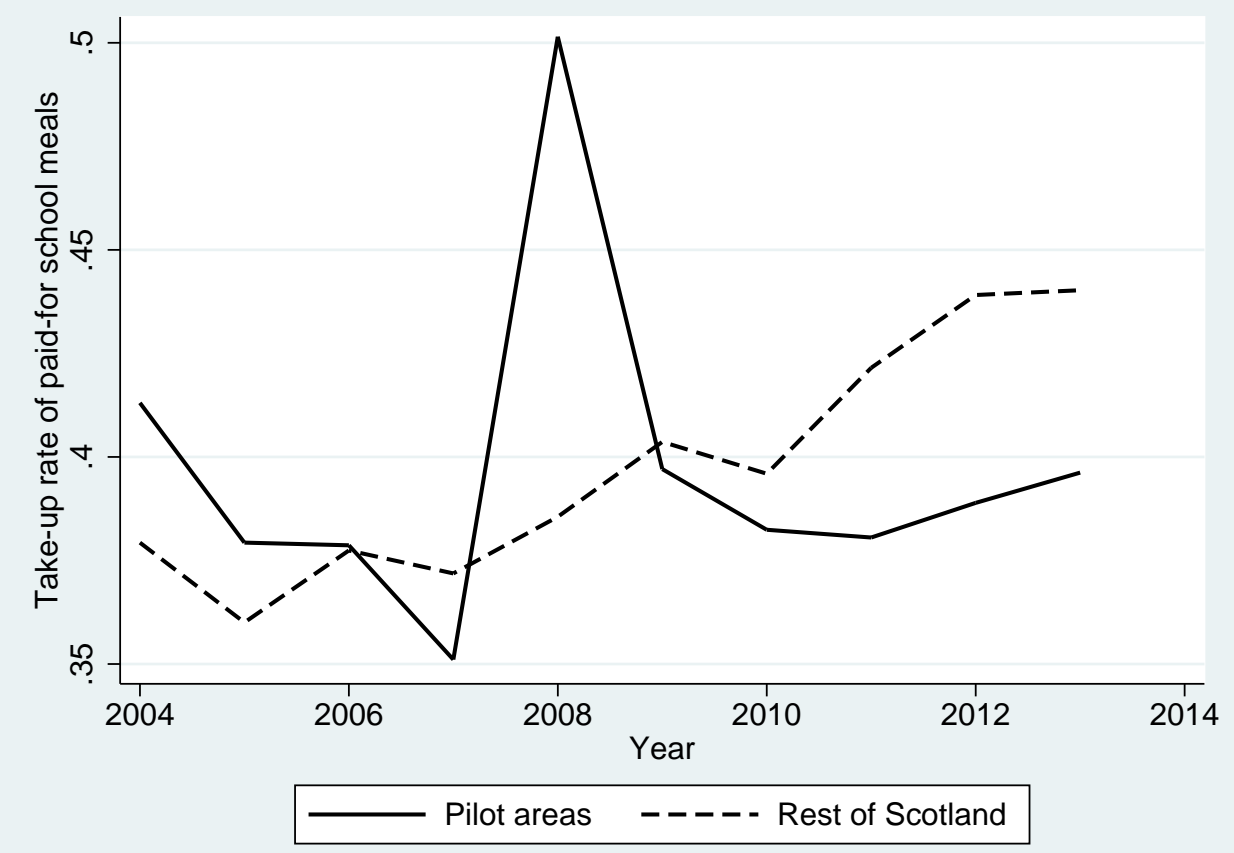

Figure 2: Take-up rate of school lunches: Pupils registered for Free School Meals

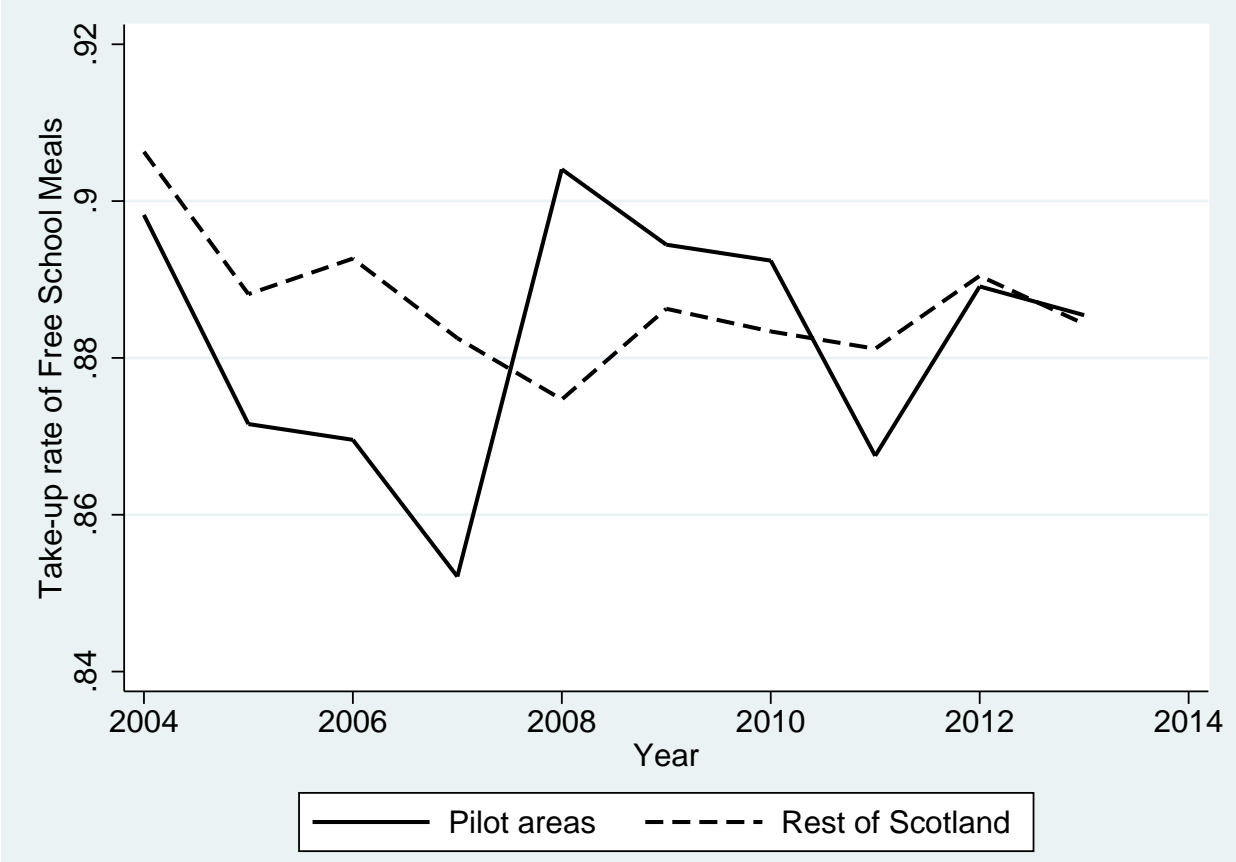


Table 1: Reduced form school fixed-effect coefficients for take-up rate of school meals, by anonymised payment status.

\begin{tabular}{lcccc}
\hline \hline & \multicolumn{2}{c}{ Not Registered for FSMs } & \multicolumn{2}{c}{ Registered for FSMs } \\
Column: & 1 & 2 & 3 & 4 \\
& Not anonymised & Anonymised & Not anonymised & Anonymised \\
Universal FSM entitlement & $\begin{array}{c}0.107^{* * *} \\
(0.026)\end{array}$ & $\begin{array}{c}0.144^{* * *}(0.021) \\
\text { Observations }\end{array}$ & $\begin{array}{c}0.035^{* *} \\
(0.011)\end{array}$ & $\begin{array}{c}0.033^{*} \\
(0.013)\end{array}$ \\
\hline Schools & 5752 & 4577 & 5626 & 4395 \\
\hline
\end{tabular}

Notes: Standard errors (clustered by LEA) in parentheses. *: $p<0.05 ; * *$ : $p<0.01 ; * * *$ : $p<0.001$. All coefficients from school and year fixed-effect linear regressions. Observations weighted in proportion to number of pupils in each category present on survey day. Additional regressors: Price, total school intake (100s), peer-group registration rate, interaction of school intake and peer-group registration, SIMD ranking percentile. 
Table 2: Selection into anonymised payment: Number of schools and proportion covered, by year.

\begin{tabular}{lccccccc}
\hline Year: & $\mathbf{2 0 0 4}$ & $\mathbf{2 0 0 5}$ & $\mathbf{2 0 0 6}$ & $\mathbf{2 0 0 7}$ & $\mathbf{2 0 0 8}$ & $\mathbf{2 0 0 9}$ & $\mathbf{2 0 1 0}$ \\
Schools with anonymised payment & 497 & 620 & 859 & 1044 & 1096 & 1199 & 1618 \\
\% of state primary schools in Scotland & 22.4 & 28.0 & 39.6 & 48.0 & 51.2 & 56.0 & 76.3 \\
\hline
\end{tabular}

Note: The number of primary schools in Scotland declined from 2,220 in 2004 to 2,121 in 2010. 
Table 3: Selection into anonymised payment: Descriptive statistics and linear probability model.

\begin{tabular}{|c|c|c|c|c|}
\hline & \multicolumn{2}{|c|}{$\begin{array}{l}\text { Mean school characteristics } \\
\text { for } 2008 \text { by anonymised } \\
\text { payment status }\end{array}$} & \multicolumn{2}{|c|}{$\begin{array}{l}\text { Linear probability model } \\
\text { for presence of } \\
\text { anonymised payment }\end{array}$} \\
\hline & $\begin{array}{l}\text { Anonymised } \\
\text { payment }\end{array}$ & $\begin{array}{l}\text { Other } \\
\text { schools }\end{array}$ & Year dummies & (Yes) \\
\hline Price $(£ s)$ & $\begin{array}{c}1.540 \\
(0.031)\end{array}$ & $\begin{array}{c}1.476 \\
(0.054)\end{array}$ & Price $(£ s)$ & $\begin{array}{c}0.056 \\
(0.226)\end{array}$ \\
\hline Universal entitlement & $\begin{array}{c}0.178 \\
(0.089)\end{array}$ & $\begin{array}{c}0.253 \\
(0.130)\end{array}$ & Current universal entitlement & $\begin{array}{l}-0.045 \\
(0.072)\end{array}$ \\
\hline Take-up rate of school meals & $\begin{array}{c}0.547 \\
(0.019)\end{array}$ & $\begin{array}{c}0.533 \\
(0.027)\end{array}$ & Take-up rate of school meals & $\begin{array}{c}0.171 \\
(0.091)\end{array}$ \\
\hline Take-up rate of FSMs & $\begin{array}{c}0.889 \\
(0.014)\end{array}$ & $\begin{array}{c}0.877 \\
(0.011)\end{array}$ & Take-up rate of FSMs & $\begin{array}{c}0.024 \\
(0.063)\end{array}$ \\
\hline Total school intake & $\begin{array}{l}179.0 \\
(13.3)\end{array}$ & $\begin{array}{l}173.2 \\
(18.5)\end{array}$ & Total school intake (100s) & $\begin{array}{c}0.002 \\
(0.015)\end{array}$ \\
\hline FSM registration rate & $\begin{array}{c}0.169 \\
(0.019)\end{array}$ & $\begin{array}{c}0.199 \\
(0.032)\end{array}$ & FSM registration rate & $\begin{array}{l}-0.135 \\
(0.209)\end{array}$ \\
\hline $\begin{array}{l}\text { SIMD percentile }(0=\text { most } \\
\text { deprived, } 1=\text { least deprived }\end{array}$ & $\begin{array}{c}0.526 \\
(0.032)\end{array}$ & $\begin{array}{c}0.431 * * \\
(0.028)\end{array}$ & $\begin{array}{l}\text { SIMD percentile }(0=\text { most } \\
\text { deprived, } 1=\text { least deprived }\end{array}$ & $\begin{array}{l}0.243^{*} \\
(0.094)\end{array}$ \\
\hline \multirow[t]{3}{*}{ Observations } & 1096 & 1044 & Observations & 9082 \\
\hline & & & Schools & 1762 \\
\hline & & & $\begin{array}{l}\text { Maximum observations } \\
\text { per school }\end{array}$ & $6(2005-2010)$ \\
\hline
\end{tabular}

Notes: Standard errors (clustered by LEA) in parentheses. Symbols for differences in means or linear probability model coefficients. *: $p<0.05 ; * *: p<0.01 ; * * *: p<0.001$. Linear probability model estimated using random effects panel data regression. Unless otherwise stated, regressors refer to lagged school characteristics. 
Table 4: Reduced form coefficients for take-up rate of school meals. (Schools with anonymised payment systems only).

\begin{tabular}{|c|c|c|c|c|}
\hline \multirow{3}{*}{ Column: } & \multicolumn{2}{|c|}{ All of Scotland } & \multicolumn{2}{|c|}{ Non-pilot areas only } \\
\hline & 1 & 2 & 3 & 4 \\
\hline & Not registered & Registered & Not registered & Registered \\
\hline Universal FSM entitlement & $\begin{array}{c}0.144^{* * *} \\
(0.021)\end{array}$ & $\begin{array}{l}0.033^{*} \\
(0.013)\end{array}$ & & . \\
\hline Price $(£)$ & $\begin{array}{c}-0.106^{* *} \\
(0.037)\end{array}$ & $\begin{array}{c}-0.074^{* *} \\
(0.026)\end{array}$ & $\begin{array}{c}-0.112^{* *} \\
(0.039)\end{array}$ & $\begin{array}{r}-0.050^{*} \\
(0.022)\end{array}$ \\
\hline Total school intake (100s) & $\begin{array}{c}-0.038^{* * *} \\
(0.010)\end{array}$ & $\begin{array}{c}0.011 \\
(0.008)\end{array}$ & $\begin{array}{l}-0.041 * * * \\
(0.011)\end{array}$ & $\begin{array}{c}0.011 \\
(0.009)\end{array}$ \\
\hline Peer-group registration rate & $\begin{array}{c}0.065 \\
(0.082)\end{array}$ & $\begin{array}{c}-0.334^{* * *} \\
(0.092)\end{array}$ & $\begin{array}{c}0.084 \\
(0.049)\end{array}$ & $\begin{array}{c}-0.327^{* *} \\
(0.108)\end{array}$ \\
\hline $\begin{array}{l}\text { Total school intake }(100 s) \times \\
\text { Peer-group registration rate }\end{array}$ & $\begin{array}{c}0.005 \\
(0.030)\end{array}$ & $\begin{array}{l}-0.038 \\
(0.028)\end{array}$ & $\begin{array}{c}0.035 \\
(0.032)\end{array}$ & $\begin{array}{l}-0.029 \\
(0.033)\end{array}$ \\
\hline $\begin{array}{l}\text { SIMD percentile }(0=\text { most } \\
\text { deprived, } 1=\text { least deprived })\end{array}$ & $\begin{array}{l}-0.062 \\
(0.074)\end{array}$ & $\begin{array}{l}-0.037 \\
(0.094)\end{array}$ & $\begin{array}{c}-0.061 \\
(0.085)\end{array}$ & $\begin{array}{l}-0.031 \\
(0.084)\end{array}$ \\
\hline Observations & 4577 & 4395 & 3786 & 3617 \\
\hline Schools & 1102 & 1033 & 900 & 834 \\
\hline $\begin{array}{l}\text { Maximum observations } \\
\text { per school }\end{array}$ & $7(2004-2010)$ & $7(2004-2010)$ & $7(2004-2010)$ & $7(2004-2010)$ \\
\hline
\end{tabular}

Notes: Standard errors (clustered by LEA) in parentheses. *: $p<0.05 ; * *$ : $p<0.01 ; * * *$ : $p<0.001$. All coefficients from school and year fixed-effect linear regressions. Observations weighted in proportion to number of pupils in each category present on survey day. 
Table 5: Structural estimates: Take-up of school meals among those registered for FSMs. (Schools with anonymised payment systems only).

\begin{tabular}{|c|c|c|c|c|c|c|c|c|c|}
\hline & \multicolumn{3}{|c|}{ All } & \multicolumn{3}{|c|}{$\begin{array}{l}\text { Price in } \\
\text { 2nd stage }\end{array}$} & \multicolumn{3}{|c|}{$\begin{array}{l}\text { Non-pilot } \\
\text { only }\end{array}$} \\
\hline & \multirow{2}{*}{$\begin{array}{c}\bar{Y}_{[-i] j t} \\
\text { 1st } \\
\text { stage }\end{array}$} & \multicolumn{2}{|c|}{$\bar{y}_{j t}^{f}$} & \multirow{2}{*}{$\begin{array}{c}\bar{Y}_{[-i] j t} \\
\text { 1st } \\
\text { stage }\end{array}$} & \multicolumn{2}{|c|}{$\bar{y}_{j t}^{f}$} & \multirow{2}{*}{$\begin{array}{c}\bar{Y}_{[-i] j t} \\
\text { 1st } \\
\text { stage }\end{array}$} & \multicolumn{2}{|c|}{$\bar{y}_{j t}^{f}$} \\
\hline & & OLS & $\begin{array}{l}\text { 2nd } \\
\text { stage }\end{array}$ & & OLS & $\begin{array}{l}\text { 2nd } \\
\text { stage }\end{array}$ & & OLS & $\begin{array}{l}\text { 2nd } \\
\text { stage }\end{array}$ \\
\hline $\begin{array}{l}\text { Peer-group } \\
\text { take-up }\left(\bar{Y}_{[-i] j t}\right)\end{array}$ & . & $\begin{array}{c}0.307^{* * *} \\
(0.054)\end{array}$ & $\begin{array}{c}0.382^{* *} \\
(0.143)\end{array}$ & . & $\begin{array}{c}0.302^{* * *} \\
(0.054)\end{array}$ & $\begin{array}{l}0.329^{*} \\
(0.149)\end{array}$ & . & $\begin{array}{c}0.279^{* * *} \\
(0.062)\end{array}$ & $\begin{array}{l}0.400^{*} \\
(0.198)\end{array}$ \\
\hline $\begin{array}{l}\text { Universal FSM } \\
\left(u_{j t}\right)\end{array}$ & $\begin{array}{c}0.102^{* * *} \\
(0.018)\end{array}$ & . & . & $\begin{array}{c}0.102^{* * *} \\
(0.018)\end{array}$ & . & . & . & . & . \\
\hline $\begin{array}{l}\text { Price }(£) \\
\left(p_{j t}\right)\end{array}$ & $\begin{array}{c}-0.133^{* * *} \\
(0.034)\end{array}$ & . & . & $\begin{array}{c}-0.133^{* * *} \\
(0.034)\end{array}$ & $\begin{array}{l}-0.033 \\
(0.022)\end{array}$ & $\begin{array}{l}-0.030 \\
(0.022)\end{array}$ & $\begin{array}{c}-0.123^{* *} \\
(0.038)\end{array}$ & . & . \\
\hline $\begin{array}{l}\text { Total school } \\
\text { intake (100s) }\end{array}$ & $\begin{array}{c}-0.038^{* * * *} \\
(0.007)\end{array}$ & $\begin{array}{l}0.022^{*} \\
(0.009)\end{array}$ & $\begin{array}{l}0.025^{*} \\
(0.011)\end{array}$ & $\begin{array}{c}-0.038^{* * *} \\
(0.007)\end{array}$ & $\begin{array}{l}0.022^{*} \\
(0.009)\end{array}$ & $\begin{array}{l}0.023^{*} \\
(0.012)\end{array}$ & $\begin{array}{c}-0.041^{* * * *} \\
(0.007)\end{array}$ & $\begin{array}{l}0.021 \\
(0.011)\end{array}$ & $\begin{array}{l}0.026^{*} \\
(0.011)\end{array}$ \\
\hline $\begin{array}{l}\text { Peer-group reg' } \\
\text { rate }\left(\rho_{[-i] j t}^{f}\right)\end{array}$ & $\begin{array}{c}0.407^{* * *} \\
(0.069)\end{array}$ & $\begin{array}{c}-0.463^{* * *} \\
(0.094)\end{array}$ & $\begin{array}{c}-0.493^{* * *} \\
(0.103)\end{array}$ & $\begin{array}{c}0.407^{* * * *} \\
(0.069)\end{array}$ & $\begin{array}{c}-0.457^{* * *} \\
(0.090)\end{array}$ & $\begin{array}{c}-0.467^{* * *} \\
(0.099)\end{array}$ & $\begin{array}{c}0.429^{* * *} \\
(0.083)\end{array}$ & $\begin{array}{c}-0.468^{* * *} \\
(0.119)\end{array}$ & $\begin{array}{c}-0.518^{* * *} \\
(0.152)\end{array}$ \\
\hline $\begin{array}{l}\text { Tot' school intake }(100 \mathrm{~s}) \\
\times \text { Peer-group reg' rate }\end{array}$ & $\begin{array}{l}0.066^{*} \\
(0.028)\end{array}$ & $\begin{array}{l}-0.059 \\
(0.032)\end{array}$ & $\begin{array}{l}-0.064 \\
(0.036)\end{array}$ & $\begin{array}{l}0.066^{*} \\
(0.028)\end{array}$ & $\begin{array}{l}-0.059 \\
(0.033)\end{array}$ & $\begin{array}{l}-0.060 \\
(0.035)\end{array}$ & $\begin{array}{l}0.064^{*} \\
(0.030)\end{array}$ & $\begin{array}{l}-0.051 \\
(0.039)\end{array}$ & $\begin{array}{l}-0.058 \\
(0.040)\end{array}$ \\
\hline $\begin{array}{l}\text { SIMD percentile } \\
(0=\text { most deprived } \\
1=\text { least deprived })\end{array}$ & $\begin{array}{l}-0.050 \\
(0.059)\end{array}$ & $\begin{array}{l}-0.018 \\
(0.097)\end{array}$ & $\begin{array}{l}-0.015 \\
(0.098)\end{array}$ & $\begin{array}{l}-0.050 \\
(0.059)\end{array}$ & $\begin{array}{l}-0.021 \\
(0.094)\end{array}$ & $\begin{array}{l}-0.020 \\
(0.096)\end{array}$ & $\begin{array}{l}-0.062 \\
(0.073)\end{array}$ & $\begin{array}{l}-0.015 \\
(0.087)\end{array}$ & $\begin{array}{l}-0.008 \\
(0.085)\end{array}$ \\
\hline $\begin{array}{l}\text { F-statistic } \\
\left(^{(p-v a l u e}\right)^{1}\end{array}$ & & $\begin{array}{l}33.024 \\
(0.000)\end{array}$ & & & $\begin{array}{l}29.256 \\
(0.000)\end{array}$ & & & $\begin{array}{l}10.184 \\
(0.004)\end{array}$ & \\
\hline $\begin{array}{l}\text { Hansen's J-statistic } \\
\text { (p-value) }^{2}\end{array}$ & & $\begin{array}{c}1.529 \\
(0.2163)\end{array}$ & & & . & & & . & \\
\hline Observations & & 4395 & & & 4395 & & & 3617 & \\
\hline Schools & & 1033 & & & 1033 & & & 834 & \\
\hline $\begin{array}{l}\text { Maximum observations } \\
\text { per school }\end{array}$ & & 7 (2004-2010) & & & 7 (2004-2010) & & & 7 (2004-2010) & \\
\hline
\end{tabular}

Notes: Standard errors (clustered by LEA) in parentheses. *: $p<0.05 ; * *$ : $p<0.01 ; * * *$ : $p<0.001$. All coefficients from school and year fixed-effect linear regressions. Observations weighted in proportion to number of FSM-registered pupils present on survey day. ${ }^{1}$ : F-statistic for exclusion of instrument(s) from first-stage regression. ${ }^{2}$ : Hansen J-statistic, testing null hypothesis that the overidentifying restrictions are valid. 
Table 6: Social multipliers on peer-group take-up: Overall effect of a 1 percentage point rise in FSM-unregistered take-up on FSM-registered take-up.

\begin{tabular}{llllc}
\hline \hline & \multicolumn{3}{c}{} \\
& \multicolumn{2}{c}{ Proportion of peers FSM-registered $\left(\rho_{[-i] j t}^{f}\right)$} \\
& $\mathbf{4 0 \%}$ & $\mathbf{2 0 \%}$ & $\mathbf{1 0 \%}$ & $\mathbf{5 \%}$ \\
Social multiplier under: & & & & \multirow{2}{*}{0.318} \\
Universal entitlement to youngest three year-groups: & 0.227 & 0.282 & 0.306 & 0.388 \\
Price reduction to all seven year-groups: & 0.286 & 0.348 & 0.375 & \\
\hline \hline
\end{tabular}




\title{
ADDITIONAL ONLINE MATERIAL FOR 'TAKE-UP OF FREE SCHOOL MEALS: PRICE EFFECTS AND PEER EFFECTS'
}

\author{
Angus Holford
}

September 22, 2014

\section{A.1 Defining the peer-group as FSM-unregistered pupils only}

Table A.1 shows the results obtained if the peer group is defined as FSM-unregistered pupils only. As discussed in section III.2, the coefficient on FSM-unregistered take-up $\left(\bar{y}_{j t}^{n}\right)$ can be interpreted as the mean (across schools) of the social multiplier $\left(\left[\delta\left(1-\rho_{[-i] j t}^{f}\right)\right] /\left[1-\gamma \rho_{[-i] j t}^{f}\right]\right)$, or overall effect of a 1 percentage point rise in FSM-unregistered take-up on FSM-registered take-up. The true social multiplier will vary across schools according to the proportion of the overall peer-group who are registered for FSMs $\left(\rho_{[i] j t}^{f}\right)$.

Substituting $\gamma=\delta=0.329$ as estimated in for the 'Price in 2nd stage' specification in Table 5, the coefficient on $\bar{y}_{j t}^{n}$ of 0.244 in the equivalent specification in Table A.1 is consistent with $\rho_{[i] j t}^{f}=$ 0.3417. This is very close to the (weighted) mean 2008 pilot area and anonymised payment $\rho_{[i] j t}^{f}$ of 0.3427 , showing that while this specification is less informative, it does yield equivalent results. The same exercise for the first specification ('All') yields $\rho_{[i] j t}^{f}=0.355$ and third specification ('non-pilot only') $\rho_{[i] j t}^{f}=0.399$. These are higher than the mean peer-group registration rates in the estimation sample. This is consistent with the majority of variation in FSM-unregistered take-up due to changes in price occurring in schools with relatively deprived intakes, proxied by higher $\rho_{j t}^{f}$.

The downward bias associated with the OLS estimate is more apparent here than in our preferred specifications, but still consistent with the interpretation that the unobserved factors leading to higher FSM-unregistered take-up also serve to reduce FSM-registered take-up. 
Table A.1: Structural estimates: Take-up of school meals among those registered for FSMs (Schools with anonymised payment systems only). Peer group defined as FSM-unregistered pupils only

\begin{tabular}{|c|c|c|c|c|c|c|c|c|c|}
\hline & \multicolumn{3}{|c|}{ All } & \multicolumn{3}{|c|}{$\begin{array}{l}\text { Price in } \\
\text { 2nd stage }\end{array}$} & \multicolumn{3}{|c|}{$\begin{array}{l}\text { Non-pilot } \\
\text { only }\end{array}$} \\
\hline & \multirow{2}{*}{$\begin{array}{c}\bar{y}_{j t}^{n} \\
\text { 1st } \\
\text { stage }\end{array}$} & \multicolumn{2}{|c|}{$\bar{y}_{j t}^{f}$} & \multirow{2}{*}{$\begin{array}{c}\bar{y}_{j t}^{n} \\
1 \mathrm{st} \\
\text { stage }\end{array}$} & \multicolumn{2}{|c|}{$\bar{y}_{j t}^{f}$} & \multirow{2}{*}{$\begin{array}{c}\bar{y}_{j t}^{n} \\
\text { 1st } \\
\text { stage }\end{array}$} & \multicolumn{2}{|c|}{$\bar{y}_{j t}^{f}$} \\
\hline & & OLS & $\begin{array}{l}\text { 2nd } \\
\text { stage }\end{array}$ & & OLS & $\begin{array}{l}\text { 2nd } \\
\text { stage }\end{array}$ & & OLS & $\begin{array}{l}\text { 2nd } \\
\text { stage }\end{array}$ \\
\hline $\begin{array}{l}\text { FSM-unregistered } \\
\text { take-up }\left(\bar{y}_{j t}^{n}\right)\end{array}$ & . & $\begin{array}{l}-0.011 \\
(0.024)\end{array}$ & $\begin{array}{l}0.285^{* *} \\
(0.105)\end{array}$ & . & $\begin{array}{l}-0.019 \\
(0.025)\end{array}$ & $\begin{array}{l}0.244^{*} \\
(0.104)\end{array}$ & . & $\begin{array}{l}-0.031 \\
(0.027)\end{array}$ & $\begin{array}{l}0.286 \\
(0.163)\end{array}$ \\
\hline $\begin{array}{l}\text { Universal FSM } \\
\left(u_{j t}\right)\end{array}$ & $\begin{array}{c}0.137^{* * * *} \\
(0.020)\end{array}$ & . & . & $\begin{array}{c}0.137^{* * * *} \\
(0.020)\end{array}$ & . & . & . & . & . \\
\hline $\begin{array}{l}\text { Price }(£) \\
\left(p_{j t}\right)\end{array}$ & $\begin{array}{l}-0.172^{* * *} \\
(0.049)\end{array}$ & . & . & $\begin{array}{l}-0.172^{* * *} \\
(0.049)\end{array}$ & $\begin{array}{l}-0.074^{* * *} \\
(0.020)\end{array}$ & $\begin{array}{l}-0.031 \\
(0.024)\end{array}$ & $\begin{array}{c}-0.172^{* *} \\
(0.055)\end{array}$ & . & . \\
\hline $\begin{array}{l}\text { Total school } \\
\text { intake (100s) }\end{array}$ & $\begin{array}{c}-0.054^{* * *} \\
(0.010)\end{array}$ & $\begin{array}{c}0.010 \\
(0.008)\end{array}$ & $\begin{array}{l}0.026^{*} \\
(0.011)\end{array}$ & $\begin{array}{l}-0.054^{* * *} \\
(0.010)\end{array}$ & $\begin{array}{c}0.009 \\
(0.008)\end{array}$ & $\begin{array}{l}0.024^{*} \\
(0.012)\end{array}$ & $\begin{array}{c}-0.057^{* * *} \\
(0.010)\end{array}$ & $\begin{array}{c}0.008 \\
(0.009)\end{array}$ & $\begin{array}{l}0.026^{*} \\
(0.012)\end{array}$ \\
\hline $\begin{array}{l}\text { Peer-group reg' } \\
\text { rate }\left(\rho_{[-i] j t}^{f}\right)\end{array}$ & $\begin{array}{c}0.126 \\
(0.083)\end{array}$ & $\begin{array}{c}-0.342^{* * *} \\
(0.102)\end{array}$ & $\begin{array}{c}-0.374^{* * *} \\
(0.103)\end{array}$ & $\begin{array}{c}0.126 \\
(0.083)\end{array}$ & $\begin{array}{c}-0.331^{* * *} \\
(-0.094)\end{array}$ & $\begin{array}{c}-0.364^{* * *} \\
(0.082)\end{array}$ & $\begin{array}{c}0.139 \\
(0.092)\end{array}$ & $\begin{array}{c}-0.348^{* *} \\
(0.125)\end{array}$ & $\begin{array}{c}-0.386^{* * *} \\
(0.114)\end{array}$ \\
\hline $\begin{array}{l}\text { Tot' school intake }(100 \mathrm{~s}) \\
\times \text { Peer-group reg' rate }\end{array}$ & $\begin{array}{c}0.041 \\
(0.050)\end{array}$ & $\begin{array}{l}-0.040 \\
(0.027)\end{array}$ & $\begin{array}{l}-0.051 \\
(0.036)\end{array}$ & $\begin{array}{l}0.041 \\
(0.050)\end{array}$ & $\begin{array}{l}-0.038 \\
(0.027)\end{array}$ & $\begin{array}{l}-0.048 \\
(0.035)\end{array}$ & $\begin{array}{c}0.028 \\
(0.052)\end{array}$ & $\begin{array}{l}-0.033 \\
(0.032)\end{array}$ & $\begin{array}{l}-0.041 \\
(0.042)\end{array}$ \\
\hline $\begin{array}{l}\text { SIMD percentile } \\
0=\text { most deprived, } \\
1=\text { least deprived) }\end{array}$ & $\begin{array}{l}-0.063 \\
(0.090)\end{array}$ & $\begin{array}{l}-0.029 \\
(0.101)\end{array}$ & $\begin{array}{l}-0.016 \\
(0.108)\end{array}$ & $\begin{array}{l}-0.063 \\
(0.090)\end{array}$ & $\begin{array}{l}-0.037 \\
(0.027)\end{array}$ & $\begin{array}{l}-0.021 \\
(0.105)\end{array}$ & $\begin{array}{l}-0.075 \\
(0.110)\end{array}$ & $\begin{array}{l}-0.034 \\
(0.086)\end{array}$ & $\begin{array}{l}-0.012 \\
(0.093)\end{array}$ \\
\hline $\begin{array}{l}\text { F-statistic } \\
(p \text {-value })^{1}\end{array}$ & & $\begin{array}{l}37.83 \\
(0.000)\end{array}$ & & & $\begin{array}{l}48.342 \\
(0.000)\end{array}$ & & & $\begin{array}{c}9.569 \\
(0.005)\end{array}$ & \\
\hline $\begin{array}{l}\text { Hansen's J-statistic } \\
\text { (p-value })^{2}\end{array}$ & & $\begin{array}{l}1.359 \\
(0.2437)\end{array}$ & & & . & & & . & \\
\hline Observations & & 4395 & & & 4395 & & & 3617 & \\
\hline Schools & & 1033 & & & 1033 & & & 834 & \\
\hline $\begin{array}{l}\text { Maximum observations } \\
\text { per school }\end{array}$ & & 7 (2004-2010) & & & 7 (2004-2010) & & & (2004-2010) & \\
\hline
\end{tabular}

Notes: Standard errors (clustered by LEA) in parentheses. *: $p<0.05 ; * *: p<0.01 ; * * *$ : $p<0.001$. All coefficients from school and year fixed-effect linear regressions. Observations weighted in proportion to number of FSM-registered pupils present on survey day. 1: F-statistic for exclusion of instrument(s) from first-stage regression. ${ }^{2}$ : Hansen J-statistic, testing null hypothesis that the overidentifying restrictions are valid. 


\section{A.2 Comparison of schools with and without anonymised payment}

In the main body of this paper, estimation is restricted to schools with anonymised payment systems. We showed that in all observable characteristics, these schools do not differ in any significant or economically important way from schools without anonymised payment.

Table A.2 compares the reduced form school and year fixed-effect regressions for take-up of school meals in schools with and without anonymised payment, in all cases for all of Scotland. In the upper section, we show the coefficients on anonymised payment in regressions for FSM-unregistered take-up and FSM-registered take-up. In the lower section, we present separate regressions for FSMregistered and non-registered pupils, by anonymised payment status. The differences between groups are revealing about the mechanisms determining take-up by the FSM-registered group, and support our decision in the main body to restrict the sample to schools with anonymised payment only.

The upper section shows that, despite the declared purpose of anonymised payment being to remove the stigma associated with being identifiable as FSM-registered, within schools the introduction of anonymised payment has no effect on the take-up rate among the FSM-registered group. In the lower section, also note that the coefficients on universal entitlement for FSM-registered students are almost identical for the two groups of schools (columns 3 and 4). Universal entitlement effectively imposes anonymisation for the affected year-groups. If that mechanism of stigma applies we would expect to see a larger positive effect on take-up for schools without anonymised payment than those with. Between these results, therefore, we find no evidence for the role of this form of stigma in reducing take-up of Free School Meals.

However, while for our estimation sample of schools with anonymised payment, the reduced-form coefficient on price is negative, large and significant (as we would expect, and consistent with the first- and second-stage instrumental variables results presented in Table 5), for the sample of schools without anonymised payment, the coefficient is positive, smaller yet still large, and also significant.

In schools without anonymised payment, an FSM-unregistered individual can distinguish between his FSM-registered and unregistered peers, and therefore see which peers are willing to pay. The positive reduced-form coefficient on price suggests within these schools, the positive signal of a higher level of the price that individuals are willing to pay dominates the lower number of individuals who are willing to pay. In the main body of this paper, we explore and reject the possibility that within schools that $d o$ have anonymised payment, the negative reduced form 
coefficient on price, in line with the hypothesised peer effect, is attenuated by a positive direct effect of the price signal.

Table A.2: Reduced form coefficients for take-up rate of school meals by school

\begin{tabular}{|c|c|c|c|c|}
\hline & \multicolumn{2}{|c|}{ Not Registered for FSMs } & \multicolumn{2}{|c|}{ Registered for FSMs } \\
\hline Anonymised payment & $\begin{aligned} 0.0( \\
(0.00\end{aligned}$ & & $\begin{array}{l}-0.0 \\
(0.00\end{array}$ & \\
\hline \multirow[t]{2}{*}{ Column: } & 1 & 2 & 3 & 4 \\
\hline & Not anonymised & Anonymised & Not anonymised & Anonymised \\
\hline Universal FSM entitlement & $\begin{array}{c}0.107^{* * *} \\
(0.026)\end{array}$ & $\begin{array}{c}0.144^{* * *} \\
(0.021)\end{array}$ & $\begin{array}{c}0.035^{* *} \\
(0.011)\end{array}$ & $\begin{array}{l}0.033^{*} \\
(0.013)\end{array}$ \\
\hline Price $(£)$ & $\begin{array}{l}-0.055 \\
(0.064)\end{array}$ & $\begin{array}{c}-0.106^{* *} \\
(0.037)\end{array}$ & $\begin{array}{l}0.048^{*} \\
(0.023)\end{array}$ & $\begin{array}{c}-0.074^{* *} \\
(0.026)\end{array}$ \\
\hline Total school intake (100s) & $\begin{array}{c}-0.034^{* * *} \\
(0.006)\end{array}$ & $\begin{array}{c}-0.038^{* * *} \\
(0.010)\end{array}$ & $\begin{array}{c}0.002 \\
(0.008)\end{array}$ & $\begin{array}{c}0.011 \\
(0.008)\end{array}$ \\
\hline Peer-group registration rate & $\begin{array}{c}0.267^{* * *} \\
(0.055)\end{array}$ & $\begin{array}{c}0.065 \\
(0.082)\end{array}$ & $\begin{array}{c}-0.402^{* * *} \\
(0.062)\end{array}$ & $\begin{array}{l}-0.334^{* * *} \\
(0.092)\end{array}$ \\
\hline $\begin{array}{l}\text { Total school intake }(100 s) \times \\
\text { Peer-group registration rate }\end{array}$ & $\begin{array}{c}0.005 \\
(0.031)\end{array}$ & $\begin{array}{c}0.055 \\
(0.030)\end{array}$ & $\begin{array}{c}-0.104^{* * *} \\
(0.012)\end{array}$ & $\begin{array}{l}-0.038 \\
(0.028)\end{array}$ \\
\hline $\begin{array}{l}\text { SIMD percentile }(0=\text { most } \\
\text { deprived, } 1=\text { least deprived })\end{array}$ & $\begin{array}{l}-0.010 \\
(0.100)\end{array}$ & $\begin{array}{l}-0.062 \\
(0.074)\end{array}$ & $\begin{array}{l}-0.019 \\
(0.061)\end{array}$ & $\begin{array}{l}-0.037 \\
(0.094)\end{array}$ \\
\hline Observations & 5752 & 4577 & 5626 & 4395 \\
\hline Schools & 1217 & 1102 & 1162 & 1033 \\
\hline $\begin{array}{l}\text { Maximum observations } \\
\text { per school }\end{array}$ & $7(2004-2010)$ & $7(2004-2010)$ & $7(2004-2010)$ & $7(2004-2010)$ \\
\hline
\end{tabular}

Notes: Standard errors (clustered by LEA) in parentheses. *: $p<0.05 ; * *$ : $p<0.01 ; * * *$ : $p<0.001$. All coefficients from school and year fixed-effect linear regressions. Observations weighted in proportion to number of pupils in each category present on survey day. 


\section{A.3 Reduced form of the estimating equation}

Section IV.5 assessed the effect of a hypothetical policy intervention on FSM participation using the 'social multiplier' for the overall effect of a change in take-up of paid-for lunches on the takeup of Free School Meals (equation A.1). This supplement shows how this is derived from the estimating equation (A.2).

$$
\begin{aligned}
& \frac{\partial E\left[\bar{y}_{j t}^{f} \mid p_{j t}, u_{j t}, \chi_{j t}\right]}{\partial E\left[\bar{y}_{j t}^{n} \mid p_{j t}, u_{j t}, \chi_{j t}\right]}=\frac{\gamma\left(1-\rho_{[-i] j t}^{f}\right)}{1-\gamma \rho_{[-i] j t}^{f}} . \\
& \begin{aligned}
E\left[\bar{y}_{j t}^{f} \mid p_{j t}, u_{j t}, \chi_{j t}\right]=\alpha+\psi \rho_{[-i] j t}^{f}+\gamma E\left[\bar{Y}_{[-i] j t} \mid p_{j t}, u_{j t}, \chi_{j t}\right] \\
+\phi \overline{\mathbf{X}}_{j t}^{f}+\theta \mathbf{Z}_{j t}+\eta_{j}+e_{t}
\end{aligned}
\end{aligned}
$$

Peer-group take-up, $\bar{Y}_{[-i] j t}$, is linearly decomposed into $\bar{y}_{j t}^{f}$ and $\bar{y}_{j t}^{n}$ according to equation (A.3):

$$
\bar{Y}_{[-i] j t}=\left(\rho_{[-i] j t}^{f} \bar{y}_{j t}^{f}\right)+\left(1-\rho_{[-i] j t}^{f}\right) \bar{y}_{j t}^{n}
$$

In addition, $\rho_{[-i] j t}^{f}$ is known for each school and $\gamma$ is estimated from equation (A.2). As such, the following expression holds for a given school and time period:

$$
\begin{aligned}
& \gamma \cdot E\left[\bar{Y}_{[-i] j t} \mid p_{j t}, u_{j t}, \chi_{j t}\right]= \\
& \gamma \cdot E\left[\left(\rho_{[-i] j t}^{f} \bar{y}_{j t}^{f}\right)+\left(\left(1-\rho_{[-i] j t}^{f}\right) \bar{y}_{j t}^{n}\right) \mid p_{j t}, u_{j t}, \chi_{j t}\right]
\end{aligned}
$$

As $\rho_{[-i] j t}^{f}$ is a known constant, the expression is linear in the conditional expectations of $\bar{y}_{j t}^{f}$ and $\bar{y}_{j t}^{n}$ (equation A.5):

$$
\begin{aligned}
& \gamma \cdot E\left[\bar{Y}_{[-i] j t} \mid p_{j t}, u_{j t}, \chi_{j t}\right]= \\
& \quad \gamma \rho_{[-i] j t}^{f} E\left[\bar{y}_{j t}^{f} \mid p_{j t}, u_{j t}, \chi_{j t}\right]+\gamma\left(1-\rho_{[-i] j t}^{f}\right) E\left[\bar{y}_{j t}^{n} \mid p_{j t}, u_{j t}, \chi_{j t}\right]
\end{aligned}
$$

Substituting this expression into equation (A.2) yields:

$$
\begin{aligned}
& E\left[\bar{y}_{j t}^{f} \mid p_{j t}, u_{j t}, \chi_{j t}\right]= \\
& \quad \alpha+\psi \rho_{[-i] j t}^{f}+\gamma \rho_{[-i] j t}^{f} E\left[\bar{y}_{j t}^{f} \mid p_{j t}, u_{j t}, \chi_{j t}\right]+\gamma\left(1-\rho_{[-i] j t}^{f}\right) E\left[\bar{y}_{j t}^{n} \mid p_{j t}, u_{j t}, \chi_{j t}\right] \\
& \quad+\phi \overline{\mathbf{X}}_{j t}^{f}+\theta \mathbf{Z}_{j t}+\eta_{j}+e_{t}
\end{aligned}
$$


This rearranges into the following reduced form, from which the coefficient on $E\left[\bar{y}_{j t}^{n} \mid p_{j t}, u_{j t}, \chi_{j t}\right]$ is recognisable as the partial derivative in equation (A.1), above:

$$
\begin{aligned}
& E\left[\bar{y}_{j t}^{f} \mid p_{j t}, u_{j t}, \chi_{j t}\right]= \\
& \quad \frac{\alpha}{1-\gamma \rho_{[-i] j t}^{f}}+\frac{\psi}{1-\gamma \rho_{[-i] j t}^{f}} \rho_{[-i] j t}^{f}+\frac{\gamma\left(1-\rho_{[-i] j t}^{f}\right)}{1-\gamma \rho_{[-i] j t}^{f}} E\left[\bar{y}_{j t}^{n} \mid p_{j t}, u_{j t}, \chi_{j t}\right] \\
& +\frac{\phi}{1-\gamma \rho_{[-i] j t}^{f}} \overline{\mathbf{X}}_{j t}^{f}+\frac{\theta}{1-\gamma \rho_{[-i] j t}^{f}} \mathbf{Z}_{j t}+\frac{\eta_{j}+e_{t}}{1-\gamma \rho_{[-i] j t}^{f}}
\end{aligned}
$$




\section{A.4 Graphs of price changes in price over time}

Figure 3: Primary school meal prices: Non-pilot areas (1)

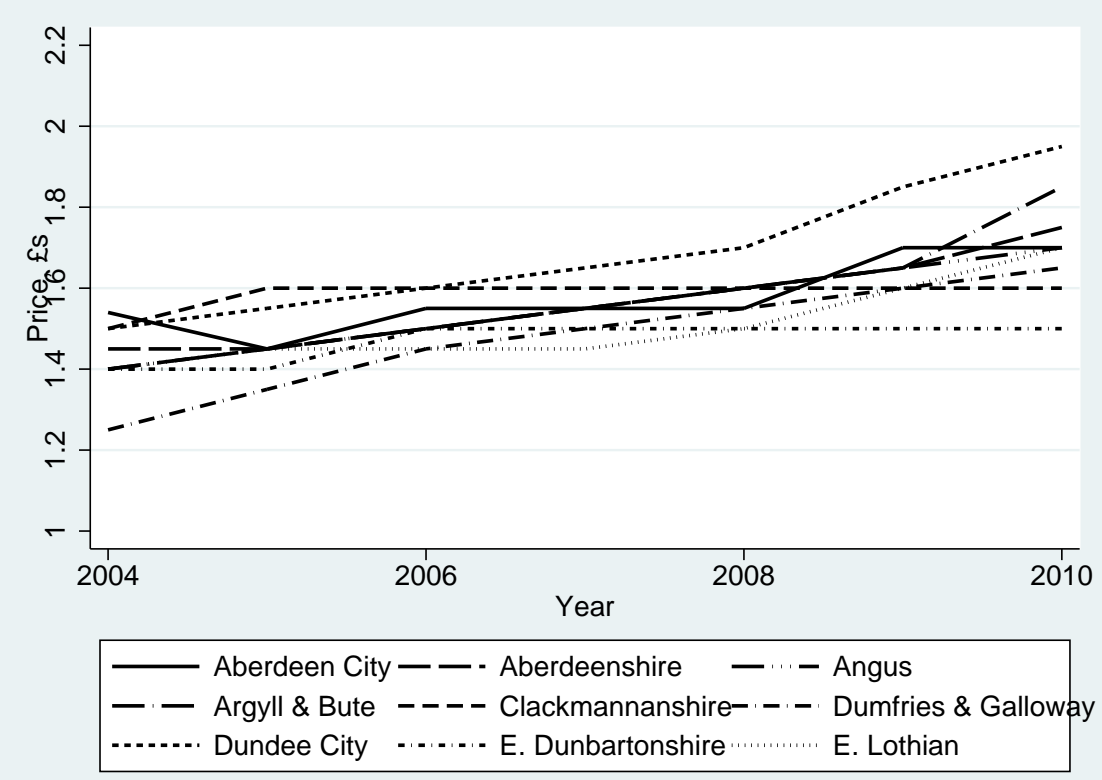

Figure 4: Primary school meal prices: Non-pilot areas (2)

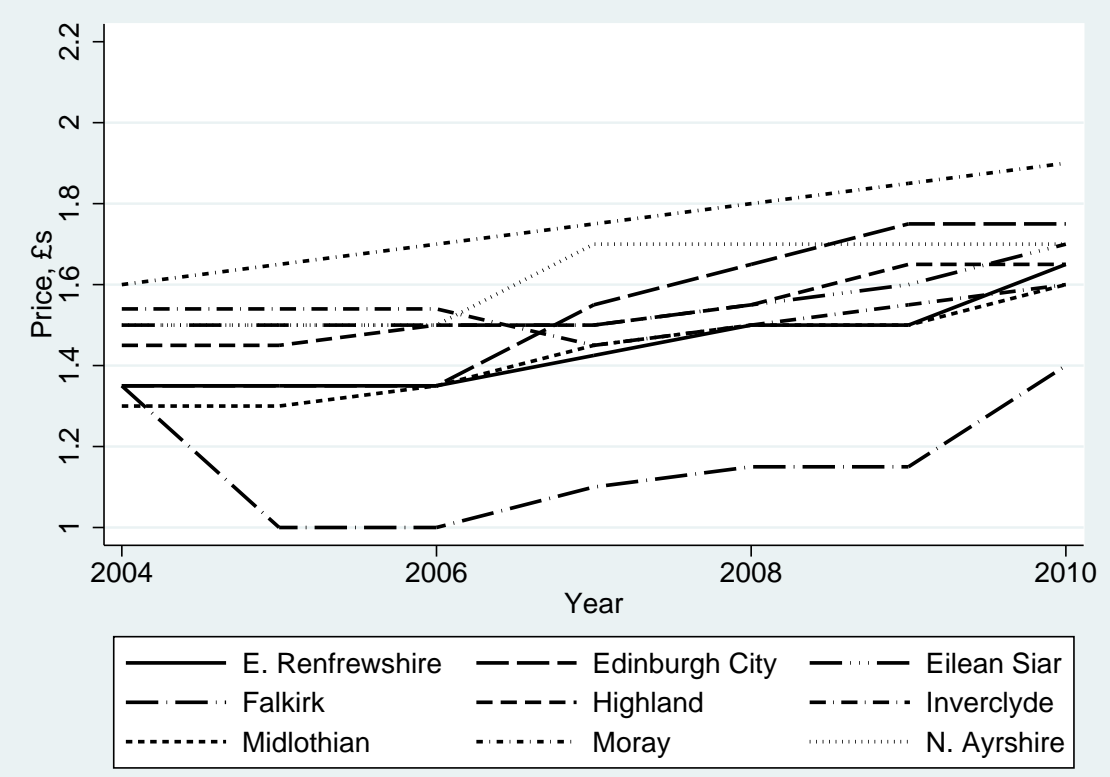


Figure 5: Primary school meal prices: Non-pilot areas (3)

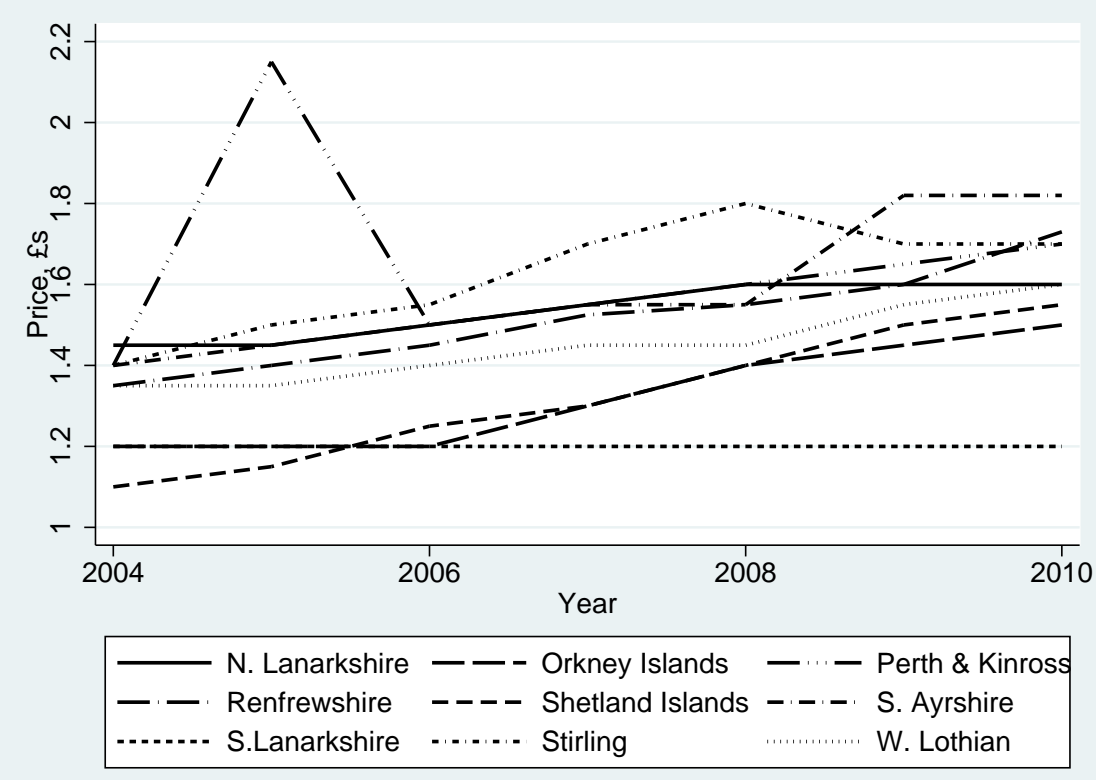

Figure 6: Primary school meal prices: Pilot areas

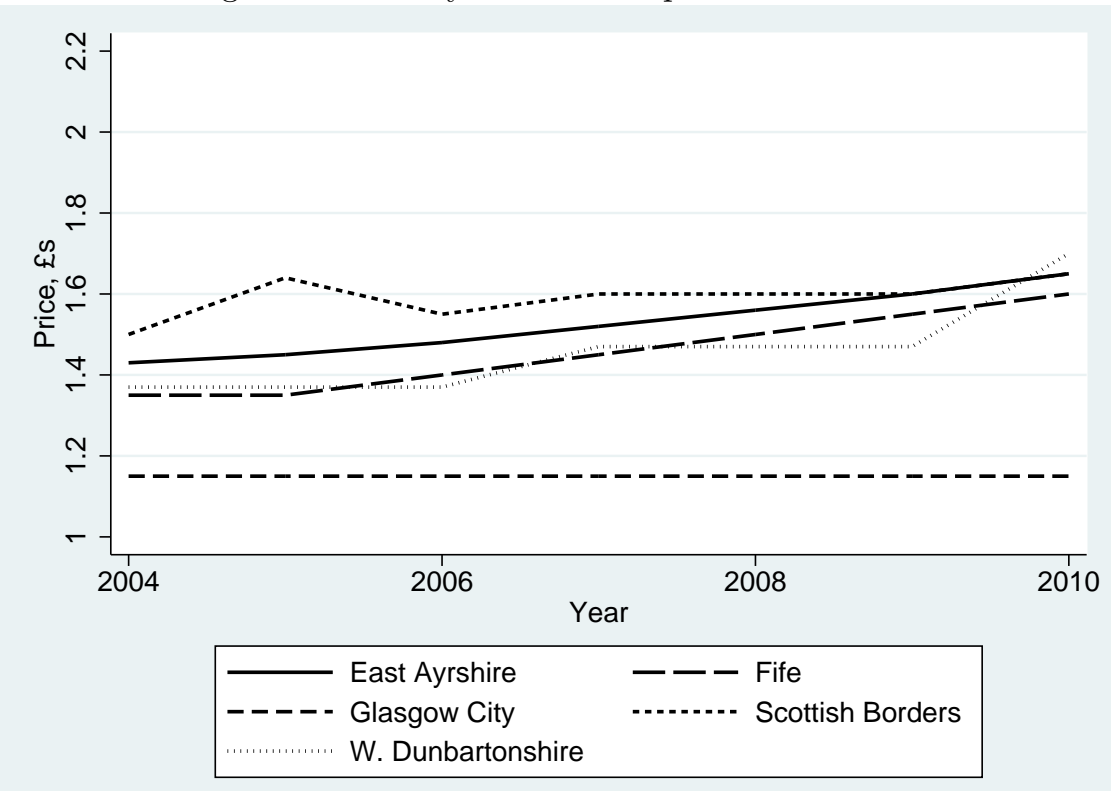

